\title{
Langmuir and Grafted Monolayers of Photochromic Amphiphilic Monodendrons of Low Generations
}

\author{
Kirsten L. Genson, Jason Holzmuller, Ovette F. Villacencio, Dominic V. McGrath, David \\ Vaknin, Vladimir V. Tsukruk
}

\section{Supporting Information}

X-ray reflectivity measurements of spread monolayers directly under UV illumination were carried out on a home built liquid-surface reflectometer. The incident beam $\left(\mathrm{CuK}_{\alpha} ; \lambda=1.5404 \AA\right)$ is selected from the white beam of a Cu-rotating-anode generator (UltraX1-18; Rigaku, Japan) by Bragg reflection from the (111) planes of a Ge single-crystal monochromator. The monochromator was situated on an arch segment that rotates the monochromator about an axis parallel to its (111) planes and the liquid-surface. Rotating this arch to an angle $t$ tilts the incident beam with respect to the surface to angle $\alpha$, given by $\sin \alpha=\left(d_{111} / \lambda\right) \operatorname{sint}$., where $d_{111}$ is the $\mathrm{Ge}(111)$ d-spacing. The motorized $\theta-2 \theta$ stages of the monochromator crystal are corrected for each tilt angle to practically track the Debye-Scherrer-cone, maintaining a fixed-energy incident-beam. Elevators are used to adjust the height of the sample and the beam-paths (with the slits) of the incident and scattered beams. The vertical divergence of the incident beam is controlled by two sets of slits (approximately $50 \mathrm{~cm}$ apart) placed between the sample and the monochromator. The divergence of the beam is varied during the experiment to roughly maintain a constant beamfootprint on the surface; beam-divergence near the critical angle is $\sim 0.01$ degrees and at the largest angle 0.09 degrees. A typical reflectivity curve takes 8-12 hours at $15 \mathrm{~kW}$ power of the X-ray generator. 
Table 1. Parameters of the box models calculated X-ray reflectivity for AA-2, AA-4, and AA-8 under ambient light conditions and AA-2 and AA-4 under $365 \mathrm{~nm}$ illumination at the air-water interface.

\begin{tabular}{|c|c|c|c|c|c|c|c|}
\hline & \multicolumn{2}{|c|}{ Head Box } & \multicolumn{2}{|c|}{ Tail Box } & \multirow[b]{2}{*}{$\begin{array}{c}\text { Roughness } \\
\text { (nm) }\end{array}$} & \multirow[b]{2}{*}{$\begin{array}{c}\text { Thickness } \\
\text { (nm) }\end{array}$} \\
\hline Sample & $\begin{array}{l}\text { Pressure } \\
(\mathrm{mN} / \mathrm{m})\end{array}$ & $\begin{array}{l}\text { Length } \\
(\mathrm{nm})\end{array}$ & $\begin{array}{c}\text { Density } \\
\left(\times 10^{3} \mathrm{e} / \mathrm{nm}^{3}\right)\end{array}$ & $\begin{array}{c}\text { Length } \\
(\mathrm{nm})\end{array}$ & $\begin{array}{c}\text { Density } \\
\left(\mathrm{x} 10^{3} \mathrm{e} / \mathrm{nm}^{3}\right)\end{array}$ & & \\
\hline \multicolumn{8}{|c|}{ Ambient Light Conditions } \\
\hline \multirow{3}{*}{ AA-2 } & 5 & 1.58 & 0.40 & 1.40 & 0.21 & 0.36 & 2.98 \\
\hline & 10 & 1.70 & 0.39 & 1.42 & 0.32 & 0.43 & 3.12 \\
\hline & 20 & 1.85 & 0.45 & 1.45 & 0.13 & 0.40 & 3.30 \\
\hline \multirow{3}{*}{ AA-4 } & 5 & 1.15 & 0.43 & 1.42 & 0.37 & 0.44 & 2.57 \\
\hline & 10 & 1.86 & 0.44 & 1.33 & 0.13 & 0.32 & 3.19 \\
\hline & 20 & 1.79 & 0.42 & 0.97 & 0.31 & 0.34 & 2.76 \\
\hline \multirow{3}{*}{ AA-8 } & 5 & 1.75 & 0.41 & 1.45 & 0.10 & 0.36 & 3.20 \\
\hline & 10 & 1.71 & 0.38 & 1.05 & 0.27 & 0.25 & 2.76 \\
\hline & 20 & 2.51 & 0.38 & - & - & 0.50 & 2.51 \\
\hline \multicolumn{8}{|c|}{$365 \mathrm{~nm}$ Light Illumination } \\
\hline \multirow{3}{*}{ AA-2 } & 5 & 1.58 & 0.35 & 1.13 & 0.30 & 0.18 & 2.71 \\
\hline & 10 & 1.84 & 0.36 & 1.05 & 0.29 & 0.15 & 2.89 \\
\hline & 20 & 1.57 & 0.35 & 1.13 & 0.30 & 0.18 & 2.70 \\
\hline \multirow{3}{*}{ AA-4 } & 5 & 1.21 & 0.36 & 1.22 & 0.33 & 0.18 & 2.43 \\
\hline & 10 & 1.93 & 0.35 & 0.82 & 0.30 & 0.08 & 2.75 \\
\hline & 20 & 1.68 & 0.35 & 0.96 & 0.31 & 0.13 & 2.64 \\
\hline
\end{tabular}




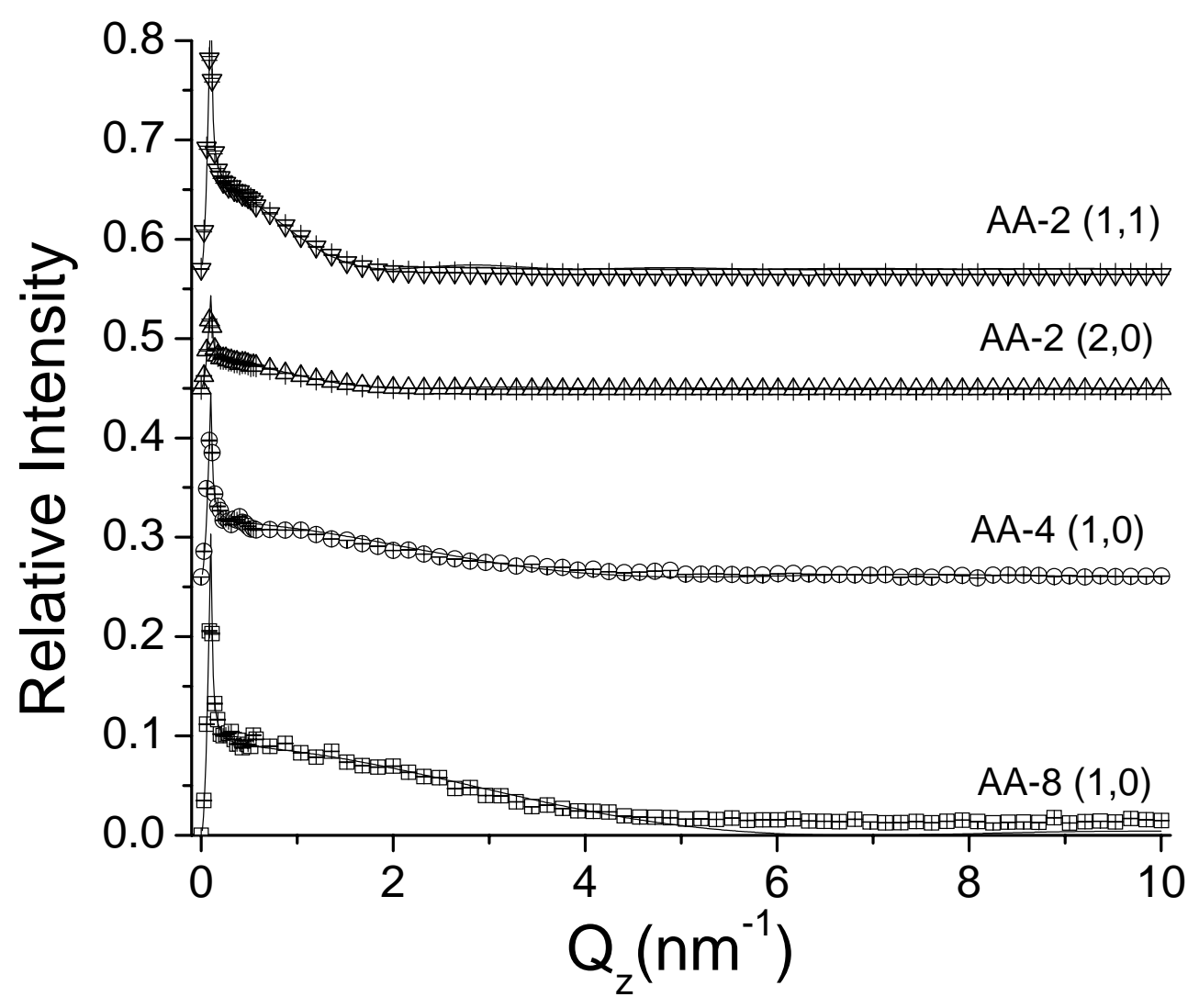

Figure 1S. Rod scans for the reflexes $(1,1)$ and $(2,0)$ for AA-2 and the $(1,0)$ for AA-4 and AA-8 with fits illustrate the perpendicular orientation of the alkyl tails. The intensities were multiplied by a factor of 10 and offset for clarity. The data are represented by symbols and the fit by lines. 

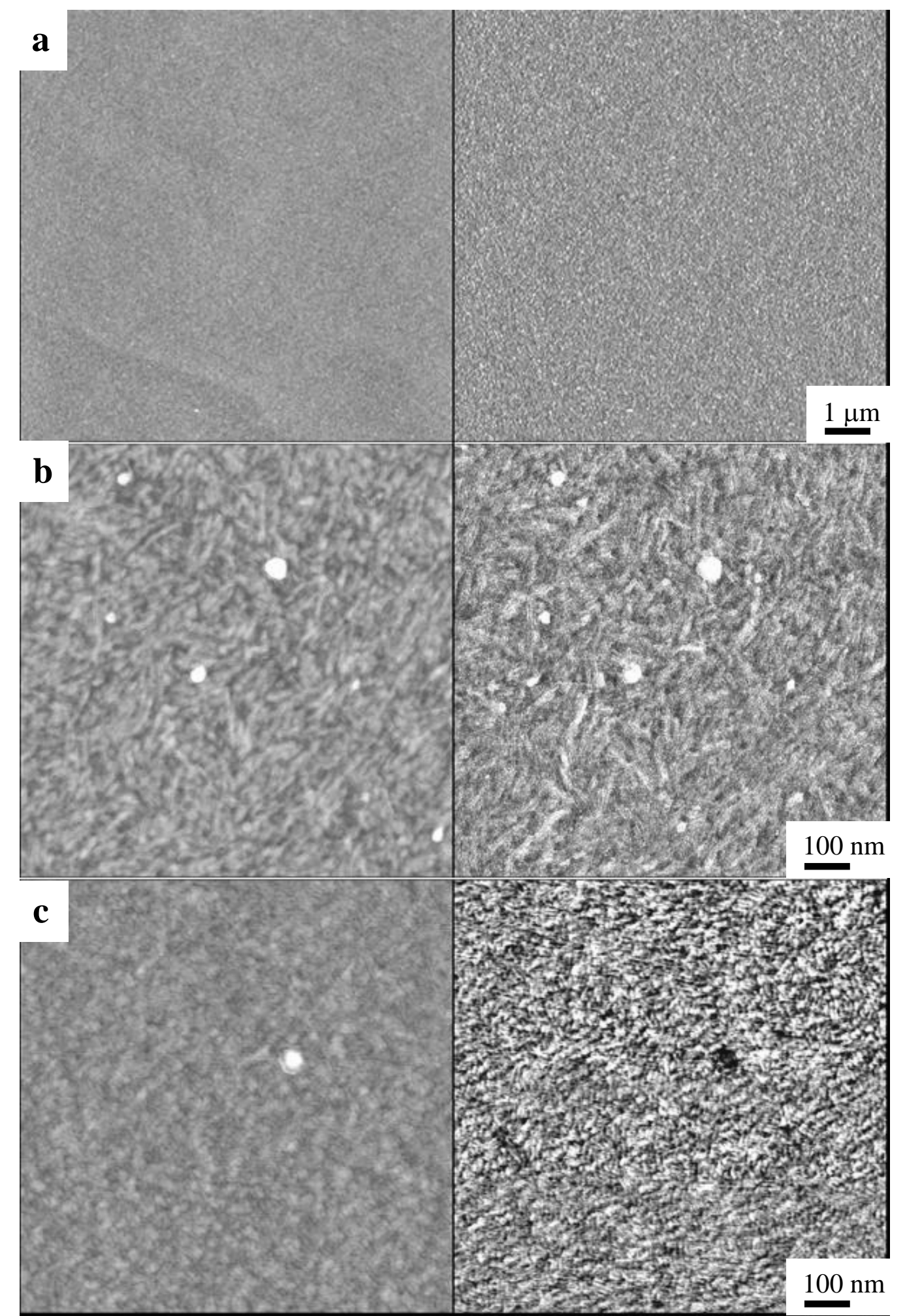

Figure 2S. The highest generations formed uniform monolayers at all surface pressures observed as shown in AFM images of a) AA-4 deposited at $5 \mathrm{mN} / \mathrm{m}$ pressure, b) AA-4 depostied at $20 \mathrm{mN} / \mathrm{m}$ pressure and c) AA-8 deposited at $20 \mathrm{mN} / \mathrm{m}$ pressure. Scale for all images: topography (left) z-range of $5 \mathrm{~nm}$, phase (right) z-range of 10 degrees. 